\title{
An Empirical Study on the Correlation Between Cruising Motivation and Cruising Intention*
}

\author{
Guo Yingzhi, Hu Tian, Huang Jianfeng, Dong Kun \\ Fudan University, Shanghai, China
}

\begin{abstract}
The cruising market is booming in China, and both motivation and intention are the most important aspects in the field of study on the cruising passengers' behaviors. The research purpose of this paper is to identify the motivation factors of the cruising passengers in China and their impact on the cruising intention. Based on the push-pull model, this paper indentified the motivation factors, including intrinsic ones and extrinsic ones, and put forward the research model. The intrinsic motivation factors include relaxation, socialization, family bonding, and social recognition, whereas the extrinsic motivation factors include entertainment and ashore tour. Having collected data through survey and analyzed them by the statistic methodology, this paper found that the motivation factors of relaxation, family bonding, entertainment, and ashore tour have a positive impact on the cruising intention, and the impact of relaxation is significant. By contrast, the motivation factors of socialization and social recognition are not positively associated with the cruising intention.
\end{abstract}

Keywords: cruising passengers, motivation, cruising intention, correlation analysis

\section{Introduction}

The cruising industry in the globe, with an average growth of 7.6\%, has been one of the fastest growing tourism sectors since the 1980s. The statistics data indicated that, within the years from 1996 to 2010, the number of the people taking the cruising vacation has increased from 6.26 million to 18.8 million, and the gross expenditures by cruising passengers have reached up to $\$ 26.8$ trillion. According to the predictions of the reliable cruising organizations like the Passenger Shipping Association (PSA), the Cruise Lines International Association (CLIA), and the European Cruise Council (ECC), the figure of the cruising passengers in the globe will grow up to 25 million in 2015 and to 30 million in 2020, respectively. In addition, the growth in the markets of Europe and Asia will be remarkable.

The center of the cruising industry worldwide has been moving eastward recently and especially, the markets of China have undergone an extraordinarily strong growth. According to the China Cruise and Yacht

\footnotetext{
* Acknowledgements: This study was supported by Grand Key Project of China National Social Science Fund (12\&ZD024), the Third Period of 985 to Whole Promotion of Social Science Research and Humane Fund at Fudan University (2012SHKXYB002), and China National Nature Science Funds (71073029\&71373054).

Guo Yingzhi, Ph.D., professor, Department of Tourism, Fudan University.

Hu Tian, Ph.D. candidate, Department of Tourism, Fudan University.

Huang Jianfeng, Ph.D. candidate, Department of Tourism, Fudan University.

Dong Kun, Ph.D. candidate, Department of Tourism, Fudan University.

Correspondence concerning this article should be addressed to Guo Yingzhi, Department of Tourism, Fudan University, Shanghai 200433, China. Email: yingzhig@hotmail.com; yingzhig@fudan.edu.cn.
} 
Industry Association (CCYIA), the number of the international cruises received by the mainland of China was 223 in 2010, up 42.9\% from the year before, of which 95 cruises depart from the coastal cities of China, up 18.75\% and 128 international cruises call upon those cities, up 68.4\%. Additionally, the number of voyage departing from Hong Kong to Taiwan was about 20 in 2010, and the 30,000 passengers were mainly from the mainland of China. The international cruises received by the Chinese mainland in 2011 were 262, up 17.5\% compared with 2010, carrying up to 504,582 passengers, of which 142 cruises depart from the coastal cities of China, up 49.5\% compared with 2010.

With the promise of the cruising industry in China, the industry focuses on one problem, that is, how to tap the new market's potential. Travel market is always bearing the prominent region attribute, for the travel motivation and the travel intention will be remarkably different, if travelers from various nations have diverse cultures, religious beliefs, and values (Baker \& Crompton, 2000). Therefore, another major problem is triggered: How to master the cruising motivation and the cruising intention, which are closely relevant to cruise lines, so as to turn more potential cruise passengers to the actual product purchasers. In this sense, the research question of this paper about the impact of the cruising motivation on the cruising intention is of high practical significance.

The purpose of this paper is to identify the motivation factors influencing the intention of the cruise passengers and to study the correlation between the cruising motivation and the cruising intention. It was recently that the academic researches on the cruising industry started from scratch and the researches on the consumer behavior of the industry are increasing. As a result, both the cruising motivation and cruising intention have become one of the major research questions. However, all the researches on the questions mentioned above merely focused on the markets except that in the mainland of China. In terms of theoretical study, the research model and the independent variables indentified and put forward by the western researchers are not appropriate for the Chinese cruising travelers. For instance, filial piety, one of the values in the eastern cultures, has an impact on the cruising intention of the Chinese. It should be noted that there is neither the research on the cruising motivation nor on the cruising intention conducted by domestic researchers. The evidence is that none of the literature with the research keywords like cruise, motivation, intention, etc., was searched out within the Chinese academic databases, such as China National Knowledge Internet (CNKI) and Wan Fang Data, on June 15, 2012.

\section{Literature Review}

As far as the relevant literature is concerned, there is no enough research on the cruising motivation and cruising intention. Qu and Ping (1999) studied the impact of cruising motivation on the intention, whereas the measurement methodology on the motivation was in light of other disciplines, and the convergent validity and discriminant validity of the instrument were not strictly tested. Hung and Petrick (2011) conducted a relevant research with a case study on cruise travelers of Florida and the United States (US), but the measurement items of motivation merely included the intrinsic factors and the extrinsic ones were not taken into account. In addition, Hung and Petrick (2012) applied the research model of motivation-opportunity-ability (MOA) in the analysis of the impacts of cruising motivation, constraints, and ability on the cruising intention. However, the relevant research on the cruising motivation and intention has not been conducted by domestic researchers, for there is evidence that none of the literature with the research keywords like cruise, motivation, intention, etc., was searched out within the Chinese academic databases, such as CNKI and Wan Fang Data, on June 15, 2012. 
Undoubtedly, motivation is the principal research topic within the fields of psychology, sociology, discipline of consumer behavior, and tourism science. Quite a few theories and concepts on travelers' motivation have been put forward. For instance, MacCannell $(1973 ; 1999)$ suggested that tourists travel to other destinations to seek authentic opportunities when their usual environments lack such an experience. Plog (1974) allocated tourists into an allocentric-psychocentric continuum in which tourists were categorized according to their personalities towards novelty-seeking and implied that personality was one of the basic sources of travel motivation. Pearce and Caltabiano (1983) applied Maslow's hierarchy of needs to the study of tourist travel motivations and suggested that experienced travelers are more likely to go on trips to fulfill a higher level of needs (i.e., self-actualization) than novice travelers. These theories imply that people travel for fulfilling certain needs and wants and that these needs and wants are the basic motivations for initiating a travel experience.

Crompton's research on travelers' motivation outstands in various relevant studies, for the push-pull model put forward by him, which mainly suggests that travelers' motivation should be deconstructed into two dimensions including push factors and pull factors, has been widely recognized by tourism scholars (Kim \& Lee, 2002).

Push factors refer to the intrinsic needs motivating travelers, which include: escape from personal/social pressures, social recognition/prestige, socialization/bonding, self-esteem, learning/discovery, regression, novelty/thrill, and distancing from crowds (Crompton, 1979; 1992). This demand-side approach helps to understand tourists' decision-making processes. Unlike push factors, pull factors are generally viewed from a supply-side perspective, mainly including the destination image, the attractions, the visible attributes related to the destination attractiveness, natural and cultural environment, tour cost, tourism infrastructure, safety, destination accessibility, etc. (Crompton, 1979; 1992).

In light of the push-pull model (Crompton, 1979), this paper presents its own research model, focusing on the cruising market in China and the consuming behavior of the Chinese.

\section{Research Model and Hypotheses}

Based on the push-pull model (Crompton, 1979) and all the elements of motivation mentioned in the literature, this paper suggests that the push factors of cruising motivation should be classified into four constructs, comprising escape/relaxation, socialization, family bonding, and social recognition, while the pull factors of cruising motivation should consist of two constructs, including entertainment and ashore tour. Family bonding is identified as the construct which suits the cruise passengers with eastern cultures. In addition, it should be mentioned that the construct of novelty, generally viewed as one construct of motivation (Hung \& Petrick, 2011), is absent in the paper, because the measurement items of family bonding and ashore tour will be overlapped, and the reason for the absence of the constructs like luxury and food and beverage is that they are not irreplaceable and unique to the cruise tourism.

For the purpose of study, this paper sets up the model and designs the following hypotheses (see Figure 1):

H1: Relaxation is positively associated with cruising intention.

$\mathrm{H} 2$ : Socialization is positively associated with cruising intention.

H3: Family bonding is positively associated with cruising intention.

H4: Social recognition is positively associated with cruising intention.

H5: Entertainment is positively associated with cruising intention.

H6: Ashore tour is positively associated with cruising intention. 


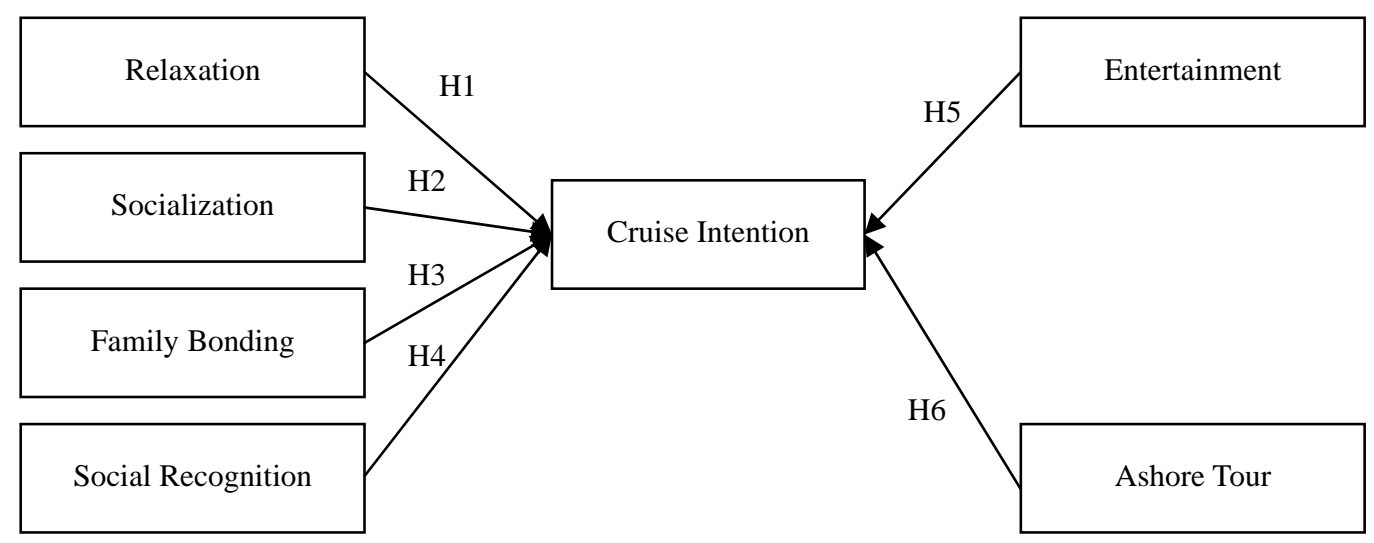

Figure 1. The relation model of cruising motivation and intention.

\section{Instrument Development and Data Collection}

Based on the past literature and review by experts, the questionnaire was designed. The questionnaire consists of seven constructs: relaxation, socialization, family bonding, social recognition, entertainment, ashore tour, and cruising intention. Items for the constructs were designed with a 7-point Likert scale, ranging from 1 (strongly disagree) to 7 (strongly agree).

To ensure that these items reflect the intended construct, content validity should be checked first. Assuming that all the possible manifestations of a construct collectively form the population of questions, content validity is the degree that the questions used in the survey for a construct provide a representative coverage of the population. The questions we used were, to a large degree, based on the rephrasing of different aspects of a construct as defined in the literature. This has provided the basis for content validity. In addition, two Ph.D. students familiar with the research project were invited to discuss the phrasing of the questions to ensure that the questions had at least face validity. Minor changes were made based on the feedback.

We carried out a random sampling survey to collect data in the Shanghai International Cruise Passenger Center (North Bund) and Wusongkou International Cruise Terminal of Shanghai in May 2012. The respondents of the survey were passengers of two cruise liners. One was the Victoria of Costa Cruise Lines, which called upon Jeju, Busan of South Korea and Fukuoka, Kagoshima of Japan. The other was the Legend of the Sea, which called upon Inchon, Jeju of South Korea and Kagoshima, Fukuoka of Japan.

The survey was carried out in two phases. Phase one was a pilot test involving 72 cruise passengers. The purpose of the pilot test was to ensure the quality of the questionnaire. After that, the main study was carried out.

\section{Pilot Study}

In the pilot test, 72 questionnaires were collected. In order to verify these questionnaires, exploratory factor analysis (EFA) was conducted to test the convergent and discriminant validity of the instrument. Convergent validity means that all the questions intended to measure a construct do reflect that construct. Discriminant validity means that a question should not reflect an unintended construct and that constructs are statistically different. EFA is an adequate tool, because it allows the underlying factors to emerge naturally from the data without imposing any constraint. If the questions for a construct are well designed, they should converge and form a major factor. If a question is problematic, it can be detected and removed from later study. 
EFA with principal component analysis was used to extract factors in our study. Following the recommended procedures, major principal components were extracted as constructs; minor principal components with eigenvalue less than 1 were ignored; an item and the unintended construct correlation should be less than 0.4 for discriminant validity. We extracted seven factors corresponding to the seven constructs using Statistical Package for Social Sciences (SPSS) 21.0, and the eigenvalue of the 6th and the 7th factors were 0.931 and 0.908 , respectively, approaching 1 . The items showed appropriate validity and were kept for the main study. Table 1 reports the principal component analysis results with varimax rotation using SPSS 21.0.

Table 1

Factor Loading for EFA of Pilot Data

\begin{tabular}{|c|c|c|c|c|c|c|c|c|}
\hline \multirow{2}{*}{ Construct } & \multirow{2}{*}{ Item } & \multicolumn{7}{|c|}{ Component } \\
\hline & & 1 & 2 & 3 & 4 & 5 & 6 & 7 \\
\hline \multirow{3}{*}{ Family bonding } & $\begin{array}{l}\text { I cruise for it suits family travel very } \\
\text { much (Bond2). }\end{array}$ & 0.871 & & & & & & \\
\hline & $\begin{array}{l}\text { I cruise to increase affections among my } \\
\text { family (Bond3). }\end{array}$ & 0.809 & & & & & & \\
\hline & $\begin{array}{l}\text { I cruise to accompany my parents } \\
\text { (Bond1). }\end{array}$ & 0.697 & & & & & & \\
\hline \multirow{3}{*}{ Cruising intention } & I shall cruise in a short period (Intent1). & & 0.900 & & & & & \\
\hline & $\begin{array}{l}\text { I shall encourage my family and friends } \\
\text { to cruise (Intent2). }\end{array}$ & & 0.849 & & & & & \\
\hline & $\begin{array}{l}\text { I shall recommend cruise to others } \\
\text { (Intent3). }\end{array}$ & & 0.784 & & & & & \\
\hline \multirow{3}{*}{ Socialization } & $\begin{array}{l}\text { I cruise to enjoy various parties on } \\
\text { cruise (Social1). }\end{array}$ & & & 0.899 & & & & \\
\hline & $\begin{array}{l}\text { I cruise for there are passengers from } \\
\text { various nations (Social2). }\end{array}$ & & & 0.886 & & & & \\
\hline & $\begin{array}{l}\text { I cruise to get chances to know new } \\
\text { friends (Social3). }\end{array}$ & & & 0.809 & & & & \\
\hline \multirow{3}{*}{ Entertainment } & $\begin{array}{l}\text { I cruise for there is casino on board } \\
\text { (Enter1). }\end{array}$ & & & & 0.881 & & & \\
\hline & $\begin{array}{l}\text { I cruise to enjoy wonderful performance } \\
\text { in the theatre (Enter2). }\end{array}$ & & & & 0.832 & & & \\
\hline & $\begin{array}{l}\text { I cruise to enjoy the wonderful games } \\
\text { (Enter3). }\end{array}$ & & & & 0.796 & & & \\
\hline \multirow{3}{*}{ Ashore tour } & $\begin{array}{l}\text { I cruise for the ship calls upon a few } \\
\text { harbor cities (Atour1). }\end{array}$ & & & & & 0.861 & & \\
\hline & $\begin{array}{l}\text { I cruise for the ashore tour is wonderful } \\
\text { too (Atour2). }\end{array}$ & & & & & 0.781 & & \\
\hline & $\begin{array}{l}\text { I shall take itinerary into more account } \\
\text { if cruising (Atour3). }\end{array}$ & & & & & 0.765 & & \\
\hline \multirow{3}{*}{ Social recognition } & $\begin{array}{l}\text { I cruise to have a high-status vacation } \\
\text { (Prest1). }\end{array}$ & & & & & & 0.820 & \\
\hline & $\begin{array}{l}\text { I cruise to get praises from my friends } \\
\text { (Prest2). }\end{array}$ & & & & & & 0.811 & \\
\hline & $\begin{array}{l}\text { I cruise to photograph an exotic place to } \\
\text { show friends (Prest3). }\end{array}$ & & & & & & 0.719 & \\
\hline \multirow{6}{*}{ Relaxation } & $\begin{array}{l}\text { I cruise to escape from the crowd } \\
\text { (Relax1). }\end{array}$ & & & & & & & 0.647 \\
\hline & I cruise to relax myself (Relax2). & & & & & & & 0.685 \\
\hline & I cruise not to relax myself (Relax3). & & & & & & & -0.839 \\
\hline & Eigenvalue & 6.509 & 3.833 & 1.958 & 1.437 & 1.145 & 0.931 & 0.908 \\
\hline & Variance (\%) & 30.99 & 18.25 & 9.326 & 6.843 & 5.452 & 4.435 & 4.276 \\
\hline & Cumulative variance (\%) & 30.99 & 49.25 & 58.57 & 65.42 & 70.87 & 75.30 & 79.58 \\
\hline
\end{tabular}




\section{Main Study and Data Analysis}

The main study involved 300 cruise passengers, yielding a total of 300 questionnaires, and 296 questionnaires were returned. However, 21 questionnaires were incomplete or invalid, and they had to be discarded, resulting in 275 questionnaires for use.

As for the demographics of the population, the male respondents accounted for $52 \%$, and the female ones accounted for $48 \%$. The age above 45 accounted for $46 \%$, between 35 and 45 accounted for $33 \%$, and between 20 and 35 accounted for $21 \%$.

Table 2 shows the descriptive statistics. Most of the constructs had a mean between 4.0 and 5.0, indicating an upward bias in the sample, comparing with a mid-point of 4 . Since regression analysis requires the data to be normally distributed, to ensure that the upward bias would not jeopardize normality, we did a univariate normality test for all items on skewness and kurtosis. A 95\% confidence level was imposed. All items fell within the corresponding confidence intervals, rendering our data suitable for further analysis.

Table 2

Descriptive Statistics and Factor Correlation

\begin{tabular}{llllllllllll}
\hline & Mean & S.D. & Min. & Max. & Intent. & Relax & Social & F.B. & S.R. & Enter. & A.T. \\
\hline Intent. & 5.507 & 0.984 & 2 & 7 & 0.879 & & & & & & \\
Relax & 5.101 & 1.022 & 2 & 7 & 0.57 & 0.849 & & & & & \\
Social & 4.232 & 1.252 & 1 & 7 & 0.31 & 0.29 & 0.834 & & & & \\
F.B. & 5.041 & 1.051 & 1 & 7 & 0.51 & 0.63 & 0.32 & 0.797 & & & \\
S.R. & 5.501 & 1.013 & 2 & 7 & -0.08 & -0.11 & -0.15 & -0.14 & 0.834 & & \\
Enter. & 4.194 & 0.818 & 2 & 7 & 0.57 & 0.56 & 0.41 & 0.43 & -0.14 & 0.786 & \\
A.T. & 5.491 & 0.996 & 2 & 7 & 0.15 & 0.03 & 0.00 & 0.03 & 0.68 & -0.05 & 0.814 \\
\hline
\end{tabular}

Notes. Intent. is the abbreviation of intention. Relax is relaxation. Social is socialization. F.B. is family bonding. S.R. is social recognition. Enter. is entertainment. A.T. is ashore tour. The correlation of the same factor is the square root of the average variance extracted (AVE).

Confirmatory factor analysis (CFA) is the conventional statistics method to specify and test such a relationship for measurement model. With this method, items are expected to be highly correlated only with the intended construct. If an item is not substantially related to the intended construct or significantly related to an unintended construct, the pre-specified relationship is invalidated and adjustment of the instrument is required. Therefore, the first requirement of CFA is that the construct-item correlation should be significant. Among the standard factor loadings, the loading of item "atour3" and its intended construct is 0.23 , which is very insignificant, and then the item "atour3" was dropped.

In addition to the significant construct-item correlation, for an item, the AVE by the latent factor should be greater than 0.5 , which means that a construct should explain more than $50 \%$ of the item variance. Moreover, items of the same construct should be highly correlated. To measure such correlations, two measures, composite factor reliability (CFR) and Cronbach's alphas ( $\alpha$ ), are required to be greater than 0.7. If all these criteria are satisfied, the convergent validity of the items is said to be confirmed. Table 3 reports the result of convergent validity for the sample using statistical package LISREL ${ }^{1}$. All criteria were satisfied.

${ }^{1}$ An acronym for linear structural relations. 
Table 3

The Convergent Validity of the Measurement Model

\begin{tabular}{|c|c|c|c|c|c|}
\hline Construct & Item & Std. loading & AVE & Cronbach's alpha & CFR \\
\hline & Intent2 & 0.99 & 0.774 & 0.907 & 0.911 \\
\hline \multirow[t]{3}{*}{ Intent. } & Intent1 & 0.82 & & & \\
\hline & Intent3 & 0.82 & & & \\
\hline & Relax3 & 0.95 & 0.722 & 0.882 & 0.885 \\
\hline \multirow[t]{3}{*}{ Relax } & Relax1 & 0.81 & & & \\
\hline & Relax2 & 0.78 & & & \\
\hline & Social1 & 0.93 & 0.696 & 0.870 & 0.871 \\
\hline \multirow[t]{3}{*}{ Social } & Social2 & 0.83 & & & \\
\hline & Social3 & 0.73 & & & \\
\hline & Bond2 & 0.88 & 0.636 & 0.831 & 0.839 \\
\hline \multirow[t]{3}{*}{ F.B. } & Bond1 & 0.82 & & & \\
\hline & Bond3 & 0.68 & & & \\
\hline & Prest1 & 0.89 & 0.696 & 0.865 & 0.873 \\
\hline \multirow[t]{3}{*}{ S.R. } & Prest2 & 0.82 & & & \\
\hline & Prest3 & 0.79 & & & \\
\hline & Enter1 & 0.96 & 0.619 & 0.950 & 0.752 \\
\hline \multirow[t]{3}{*}{ Enter. } & Enter2 & 0.94 & & & \\
\hline & Enter3 & 0.90 & & & \\
\hline & Atour1 & 0.69 & 0.663 & 0.851 & 0.854 \\
\hline \multirow[t]{2}{*}{ A.T. } & Atour2 & 0.86 & & & \\
\hline & Atour3 & 0.88 & & & \\
\hline
\end{tabular}

Notes. Intent. is the abbreviation of intention. Relax is relaxation. Social is socialization. F.B. is family bonding. S.R. is social recognition. Enter. is entertainment. A.T. is ashore tour.

One way to confirm the discriminant validity is to check that the inter-construct correlation is less than the square root of AVE. The underlying rationale is that an item should be better explained by its intended constructs than by some other constructs. The correlation among constructs is reported in Table 2. Discriminant validity was confirmed in our sample.

\section{Testing of Hypotheses}

Since the measurement model was satisfactory, we proceeded to test hypotheses. Before any conclusions can be drawn for testing the hypotheses, the model must fit the data well. A few model-fitting indices can be employed here: standard chi-square $=1.304<3$, root mean square error approximation $($ RMSEA) $=0.044<0.1$, comparative fit index $(\mathrm{CFI})=0.98>0.9$, incremental fit index $(\mathrm{IFI})=0.98>0.9$, and adjusted goodness-of-fit index $($ AGFI $)=0.89$. Our results indicated satisfactory model fit.

In our measurement model, the dependent variable was cruising intention, while the independent variables were relaxation, socialization, family bonding, social recognition, entertainment, and ashore tour. Based on the hypotheses, the regression equation was presented:

$$
\text { Intent. }=\beta_{0}+\beta_{1} \text { Relax }+\beta_{2} \text { Social }+\beta_{3} \text { F.B. }+\beta_{4} \text { S.R. }+\beta_{5} \text { Enter } .+\beta_{6} \text { Atour }+\zeta
$$

After the scatter-plot analysis, we found that there is a linear correlation. And then, we proceeded with both the regression analysis and the hypotheses testing. Table 4 shows the results. 
As Table 4 shows, such independent variables as relaxation $\left(\beta_{1}=0.316, p=0.000\right)$, family bonding $\left(\beta_{3}=0.170, p=0.036\right)$, entertainment $\left(\beta_{5}=0.234, p=0.002\right)$, and ashore tour $\left(\beta_{6}=0.176, p=0.031\right)$ are positively associated with cruising intention. Thus, H1, H3, and H5 were supported. Moreover, the correlation between relaxation and cruising intention is highly positive. The rest of the independent variables, social recognition $\left(\beta_{2}=0.040, p=0.573\right)$ and socialization $\left(\beta_{4}=0.075, p=0.361\right)$, are not positively associated with cruising intention. Thus, $\mathrm{H} 2$ and $\mathrm{H} 4$ were not supported.

Table 4

Regression Analysis and Hypotheses Testing

\begin{tabular}{|c|c|c|c|c|c|c|c|c|}
\hline Hypothesis & $\begin{array}{l}\text { Independent } \\
\text { variable }\end{array}$ & $\begin{array}{l}\text { Dependent } \\
\text { variable }\end{array}$ & Standard $\beta$ & $T$-test & Sig. & $R^{2}$ & $F$-test & Result \\
\hline 1 & Relax & Intent. & $\beta_{1}=0.316$ & 3.759 & 0.000 & 0.393 & 15.970 & Supported \\
\hline 2 & Social & Intent. & $\beta_{2}=0.040$ & 0.565 & 0.573 & & & Not supported \\
\hline 3 & F.B. & Intent. & $\beta_{3}=0.170$ & 2.120 & 0.036 & & & Supported \\
\hline 4 & S.R. & Intent. & $\beta_{4}=0.075$ & 0.916 & 0.361 & & & Not supported \\
\hline 5 & Enter. & Intent. & $\beta_{5}=0.234$ & 3.121 & 0.002 & & & Supported \\
\hline 6 & A.T. & Intent. & $\beta_{6}=0.176$ & 2.172 & 0.031 & & & Not supported \\
\hline
\end{tabular}

\section{Conclusions}

The results of the data analysis indicated that the motivation of relaxation is positively associated with cruising intention. Their highly positive correlation was consistent with the attribute of cruise, the type of vacation tour. The emergence and rise of cruise marked the transformation of tourists' values, from fast sightseeing to slow tour experience (Pearce \& Caltabiano, 1983). Tourists have attached more importance to their own sustainable development, to the harmony with nature, to the value of experience, and to their own health, which resulted in the changes in their tour types (MacCannell, 1999). Cruise, a tourism product of vacation type, known as a floating resort or a floating tiny town, seems wonderfully suitable for tourists' motivation of relaxation and their value of experience (Lois, Wang, Wall, \& Ruxton, 2004). So, the function of relaxation should be highlighted when the cruise line promotes its products.

The positive correlation of family bonding and cruising intention demonstrated that a cruise is appropriate to the family tour. Tourists with an eastern culture background considered family as one of their core values. A few unique traditions of eastern culture turned out to be the motivation factors influencing cruise travelers' intention. Our survey indicated that a large proportion of aged passengers took the cruise vacation which was purchased by their children. It was filial piety that was the major motivation factor triggering cruising intention. The vacation type, relatively settled space, and slow experience resulted in cruise being viewed as a major alternative of family tour (Yarnal \& Kerstetter, 2005). Therefore, the product design and promotion by a cruise line ought to meet demands for affection bonding of the family within each phase of the life cycle.

The relatively significant correlation of entertainment and cruising intention accounted for entertainment's importance in influencing cruising passengers' consuming decisions. Diverse performances, games, and casino on ship are unique to the cruise and should be the advantages of cruise promotion (Petrick, Li, \& Park, 2007). For example, it was for its philosophy of fun ship that the sensation was created by the Carnival Cruise Lines in the 1960s. Another thing which needs to be noted is that there is a gap of recognition among passengers from various nations because of the difference in their consuming psychology and cultures. As an example, Italian opera is presented by Carnival's cruise when its voyage is on the Mediterranean, while the Broadway opera 
would be the alternative when the cruise floats on the Caribbean. The cruise line has to consider how to localize entertainment products.

The itinerary of cruise was another major factor impacting the potential passengers' decisions. Apart from the home port, a few call-upon ports were the major knots on the cruise's route (MacCannell, 1973), and the ashore tour, with the center of a call-upon port, had the limited space of a cruise expanded largely (Jaakson, 2004). When a potential passenger made a purchase decision, the call-upon ports and the ashore tours on them would be weighed too much besides the destination. However, the call-upon ports selected by the cruise line were mainly the coastal cities with the developed tourism, and the ashore tours were generally sightseeing and shopping, which resulted in an unobvious advantage of tour by cruise to that by air. The design of itinerary and ashore tour should be innovative and meet the demand of passengers for novelty.

Theoretically, it seemed to a cruise that socialization should be one of the motivation factors impacting the intention for a ship, as a carrier has the settled space. However, the data analysis indicated that the motivation of relaxation was highly positively correlated with intention. One major reason is that the respondents of our survey were passengers with an eastern culture background. The eastern culture thinks highly of a reserved person and the Chinese passengers stamped by the culture had a weak motivation for sociable parties. That gave a hint to the cruise line that simply copying the products for the Europeans and Americans was definitely wise. There is a large difference in the motivation and consuming behavior of passengers from various nations for their diverse cultures, values, and religious beliefs.

Although the tour by cruise can be classified into the tourism product of high scale, the motivation of social recognition was definitely not the major factor influencing the potential passengers' intention. One reason was that with the travelers getting more experienced, the motivation of prestige through travelling had been weakened. The other reason was that a few price-sensitive travelers had become cruise passengers as a result of the various promotion ways employed by cruise lines (Petrick, 2005), in order to expand their market shares. Under the circumstances mentioned above, the motivation of social recognition had an ineffective impact on cruising intention.

\section{References}

Baker, D. A., \& Crompton, J. L. (2000). Quality, satisfaction, and behavioral intentions. Annals of Tourism Research, 27(3), 785-804.

Crompton, J. L. (1979). Motivations for pleasure vacation. Annals of Tourism Research, 6(4), 408-424.

Crompton, J. L. (1992). Structure of destination choice sets. Annals of Tourism Research, 19(3), 420-434.

Hung, K., \& Petrick, J. F. (2011). Why do you cruise? Exploring the motivations for taking cruise holidays, and the construction of a cruising motivation scale. Tourism Management, 32(2), 386-393.

Hung, K., \& Petrick, J. F. (2012). Testing the effects of congruity, travel constraints, and self-efficacy on travel intentions: An alternative decision-making model. Tourism Management, 33(4), 855-867.

Jaakson, R. (2004). Beyond the tourist bubble? Cruiseship passengers in port. Annals of Tourism Research, 31(1), 44-60.

Kim, S. S., \& Lee, C. K. (2002). Push and pull relationships. Annals of Tourism Research, 29(1), 257-260.

Lois, P., Wang, J., Wall, A., \& Ruxton, T. (2004). Formal safety assessment of cruise ships. Tourism Management, 25(1), 93-109.

MacCannell, D. (1973). Staged authenticity: Arrangements of social space in tourist settings. American Journal of Sociology, 79(3), 589-603.

MacCannell, D. (1999). Staged authenticity. In The tourist: A new theory of the leisure class (3rd ed.; pp. 91-107). Berkeley: University of California Press.

Pearce, P. L., \& Caltabiano, M. L. (1983). Inferring travel motivation from travelers' experiences. Journal of Travel Research, 22(2), 16-20. 
Petrick, J. F. (2005). Segmenting cruise passengers with price sensitivity. Tourism Management, 26(5), 753-762.

Petrick, J. F., Li, X., \& Park, S. Y. (2007). Cruise passengers' decision-making processes. Journal of Travel and Tourism Marketing, 23(1), 1-14.

Plog, S. C. (1974). Why destination areas rise and fall in popularity? Cornell Hotel and Restaurant Quarterly, 14(4), 55-58.

Qu, H., \& Ping, E. W. Y. (1999). A service performance model of Hong Kong cruise travelers' motivation factors and satisfaction. Tourism Management, 20(2), 237-244.

Yarnal, C. M., \& Kerstetter, D. (2005). Casting off: An exploration of cruise ship space, group tour behavior, and social interaction. Journal of Travel Research, 43(4), 368-379. 